extracts: requirement for dATP and cytochrome $c$. Cell 86, 147-157 (1996).

9. Kluck, R. M., Bossy-Wetzel, E., Green, D. R. \& Newmeyer, D. D. The release of cytochrome $c$ from mitochondria: a primary site for Bcl-2 regulation of apoptosis. Science 275, 1132-1136 (1997).

10. Martin, S. J. \& Green, D. R. Protease activation during apopotosis: death by a thousand cuts? Cell 82, 349-352 (1995).

11. Muzio, M. et al. Flice, a novel FADD-homologous ICE/CED-3-like protease, is recruited to the CD95 (Fas/APO-1) death-inducing signaling complex. Cell 85, 817-827 (1996).

12. Boldin, M. P., Goncharov, T. M., Goltsev, Y. V. \& Wallach, D. Involvement of MACH, a novel MORT1/ FADD-interacting protease, in Fas/APO-1 and TNF receptor-induced cell death. Cell 85, 803-815 (1996).

13. Srinivasula, S., Ahmad, M., Fernandes-Alnemri, T., Litwack, G. \& Alnemri, E. S. Molecular ordering o the fas-apoptotic pathway: The fas/APO-1 protease Mch5 is a CrmA-inhibitable protease that activates multiple Ced-3/ICE-like cysteine proteases. Proc. Natl Acad. Sci. USA 93, 14486-14491 (1996).

14. Muzio, M., Salvesen, G. S. \& Dixit, V. M. FLICE induced apoptosis in a cell-free system. J. Biol. Chem 272, 2952-2956 (1997)

15. Martin, S. J. et al. Cell-free reconstitution of Fas-, UV radiation- and ceramide-induced apoptosis. EMBO J. 14, 5191-5200 (1995).

16. Quan, L. T. et al. Proteolytic activation of the cell death protease Yama/CPP32 by granzyme B. Proc Natl Acad. Sci. USA 93, 1972-1976 (1996).

17. Zhou, Q. et al. Target protease specificity of the viral serpin CrmA: analysis of five caspases. J. Biol. Chem. 272, 7797-7800 (1997).

18. Bertin, J. et al. Apoptotic suppression by baculovirus p35 involves cleavage by and inhibition of a virus-induced CED-3/ICE-like protease. J. Virol. 70, 6251-6259 (1996).

19. Xiang, J., Chao, D. T. \& Korsmeyer, S. J. BAX-induced cell death may not require interleukin $1 \beta$ converting enzyme-like proteases. Proc. Natl Acad. Sci. USA 93, 14559-14563 (1996).

20. Weil, M. et al. Constitutive expression of the machinery for programmed cell death. J. Cell Biol. 133, 1053-1059 (1996)

21. Kuida, K. et al. Altered cytokine export and apoptosis in mice deficient in interleukin- $1 \beta$ converting enzyme. Science 267, 2000-2003 (1995).

22. Kuida, K. et al. Decreased apoptosis in the brain and premature lethality in CPP32-deficient mice. Nature 384, 368-372 (1996).

23. Yamakawa, T. et al. Increase of solubility of foreign proteins in Escherichia coli by coproduction of the bacterial thioredoxin. J. Biol. Chem. 270, 25328-25331 (1995).

24. Hanada, M., Aimé-Sempé, C., Sato, T. \& Reed, J. C. Structure-function analysis of Bcl-2 protein identification of conserved domains important for homodimerization with Bcl-2 and heterodimerization with Bax. J. Biol. Chem. 270, 11962-11968 (1995).

25. Sato, T., Irie, S. \& Reed, J. C. A novel member of the TRAF family of putative signal transducing proteins binds to the cytosolic domain of CD40. FEBS Lett. 358, 113-118 (1995).

26. Deveraux, Q., van Nocker, S., Mahaffey, D., Vierstra, R. \& Rechsteiner, M. Inhibition of ubiquitinmediated proteolysis by the Arabidopsis $26 \mathrm{~S}$ protease subunit S5a. J. Biol. Chem. 270, 29660-29663 (1995).

27. Krajewski, S. et al. Immunolocalization of the ICE/Ced-3-family protease, CPP32 (caspase-3), in nonHodgkin's lymphomas (NHLs), chronic lymphocytic leukemias (CLL), and reactive lymph nodes. Blood (in the press).

28. Orth, K., O'Rourke, K., Salvesen, G. S. \& Dixit, V. M. Molecular ordering of apoptotic mammalian CED-3/ICE-like proteases. J. Biol. Chem. 271, 20977-20980 (1996).

Acknowledgements. We thank A. Price and Q. Zhou for technical assistance, N. Roy, M. Ellerby, and L. Ellerby for discussion, N. Thornberry for ICE and V. Dixit for some protease-encoding cDNAs and antibodies.

Correspondence and requests for materials should be addressed to J.C.R. (e-mail: jreed@ljcrf.edu)

\section{Drosophila Mad binds to DNA and directly mediates activation of vestigial by Decapentaplegic}

\author{
Jaeseob Kim, Kirby Johnson $\dagger$, Hui Ju Chen $\ddagger$, \\ Sean Carroll ${ }^{\star}+$ \& Allen Laughon $\dagger$
}

* Howard Hughes Medical Institute and Laboratory of Molecular Biology, University of Wisconsin, 1525 Linden Drive, Madison, Wisconsin 53706, USA $\dagger$ Departments of Genetics and Medical Genetics, 445 Henry Mall, University of Wisconsin-Madison, Madison, Wisconsin 53706, USA $\$$ Department of Oncology, McArdle Laboratory, University of Wisconsin-Madison, Madison, Wisconsin 53706, USA

The TGF- $\beta$ (transforming growth factor- $\beta$ )-related signalling proteins, including Decapentaplegic (Dpp) in Drosophila and bone morphogenic proteins and activin in vertebrates, affect the growth and patterning of a great variety of structures. However, the mechanisms by which these ligands regulate gene expression are not understood. Activation of complexes of type I with type II receptors results in the phosphorylation and nuclear localization of members of the SMAD protein family ${ }^{1-9}$, which are thought to act as co-activators of transcription, perhaps in conjunction with sequence-specific cofactors ${ }^{10}$. Here we show that the aminoterminal domain of the Drosophila Mothers against $d p p$ protein (Mad), a mediator of Dpp signalling ${ }^{11-14}$, possesses a sequencespecific DNA-binding activity that becomes apparent when carboxy-terminal residues are removed. Mad binds to and is required for the activation of an enhancer within the vestigial wingpatterning gene in cells across the entire developing wing blade. Mad also binds to Dpp-response elements in other genes. These results suggest that Dpp signalling regulates gene expression by activating Mad binding to target gene enhancers.

In the Drosophila wing imaginal disc, the anteroposterior and dorsoventral compartment boundaries are important signalling sources, and inputs from both axes are required for appendage formation ${ }^{15}$. Growth and patterning along the anteroposterior axis depends upon the sequential organizing activities of the Engrailed (En), Hedgehog (Hh) and Decapentaplegic (Dpp) proteins ${ }^{16-19}$. Dpp acts as a morphogen from its source to organize wing growth and anteroposterior patterning and to activate gene expression over a long range ${ }^{19-24}$. The spalt $(\text { sal })^{25}$ and optomotor-blind $(\mathrm{omb})^{26}$ genes are expressed in nested patterns centred on and extending up to 20 cell-diameters away from the stripe of Dpp expression $^{22,23}$ (Fig. 1a). The vestigial ( $v g$ ) gene is even more broadly expressed and is required in all cells of the developing wing (Fig. 1a). Activation of $v g$ is regulated by signals from both axes through separate cis-regulatory elements that control complementary patterns of gene expression ${ }^{24}$. The 'boundary' enhancer is activated along the dorsoventral boundary through components of the Notch pathway, whereas the 'quadrant' enhancer is activated in the remainder of the developing wing blade (Fig. 1e) by Dpp as well as a signal from the dorsoventral boundary ${ }^{24}$.

Because Mad is an intracellular signal transducer downstream of Dpp receptors ${ }^{1,13,14}$, we examined the requirement of Mad activity for $\mathrm{Vg}$ expression in the wing imaginal disc in mitotic clones with reduced Mad function. Homozygous clones for the strong Mad $\mathrm{M}^{1.2}$ allele in developing wing-blade cells had significantly reduced levels of $\mathrm{Vg}$ expression and showed a growth disadvantage in comparison with surrounding heterozygous or wild-type cells (twin spot) (Fig. $1 \mathrm{~b}-\mathrm{d}$, arrows). In contrast, $\mathrm{Mad}^{1.2}$ clones along the dorsoventral boundary did not show any changes in Vg expression levels (Fig. $1 \mathrm{~b}-\mathrm{d}$, arrowheads). The different effects of the reduction of Mad activity in dorsoventral boundary versus wing-blade clones is explained by the different regulatory elements that control the expression of the $v g$ gene in these regions. Mad has no effect on the Notch-dependent dorsoventral boundary enhancer, but the quadrant enhancer required Dpp signalling ${ }^{24}$ and Mad function.

To investigate whether Mad exerts a direct effect on $v g$ transcription, we tested whether Mad could bind specifically to the quadrant enhancer. SMAD family members share highly conserved aminoand carboxy-terminal domains, termed MAD homology regions 1 and 2 (MH1 and $\mathrm{MH} 2)^{2}$, which are separated by a less conserved proline-rich linker region. We found that the Mad MH1 plus linker, expressed as a glutathione $S$-transferase (GST) fusion protein $\left(\right.$ designated $\mathrm{Mad}^{\mathrm{N}}$ ), bound DNA and protected a single interval within the quadrant enhancer in a DNase I footprinting experiment (Fig. 2a); GST and the GST-MAD linker plus MH2 fail to bind DNA (data not shown). The specificity of Mad binding to these protected sequences was demonstrated by a gel mobility-shift assay (Fig. 2b). A 39-base-pair double-stranded oligonucleotide of the $v g$ quadrant enhancer containing the Mad-protected region, the $\mathrm{Q}^{+}$probe, was bound readily by $\mathrm{Mad}^{\mathrm{N}}$ (Fig. 2b, lane 2). A double-stranded oligonucleotide in which $12 \mathrm{bp}$ of the $\mathrm{Mad}^{\mathrm{N}}$ protected region was replaced with two BglII restriction sites, the $\mathrm{Q}^{\mathrm{m}}$ probe, was bound with much lower affinity than the wild-type sequence (Fig. 2b, lane 7). Moreover, the $\mathrm{Q}^{\mathrm{m}}$ mutant oligonucleotide did not compete as efficiently as the $\mathrm{Q}^{+}$oligonucleotide with the ${ }^{32} \mathrm{P}$-labelled $\mathrm{Q}^{+}$probe (Fig. 2b, compare lanes 3 and 4 with lanes 5 and 6). These data suggest that the binding of $\mathrm{Mad}^{\mathrm{N}}$ protein to the quadrant enhancer 
is specific. Only a single predominant band shift was observed, regardless of competitor concentration (Fig. 2b, lanes 2-6). These results suggest that $\mathrm{Mad}^{\mathrm{N}}$ binds to DNA as a single species.

To test whether the $\mathrm{Mad}^{\mathrm{N}}$ binding site is essential for the activation of the quadrant enhancer in vivo, we generated transgenic fly lines carrying a lac $Z$ reporter gene under the control of the quadrant enhancer in which the $12 \mathrm{bp}$ of the footprinted interval were replaced with one or two 6-bp BglII restriction sites, the 12-bp substitution corresponding in sequence to the $\mathrm{Q}^{\mathrm{m}}$ oligonucleotide that fails to bind $\mathrm{Mad}^{\mathrm{N}}$. Normally, the quadrant enhancer is activated in early third-instar discs as a small patch of expression near the intersection of the anteroposterior and dorsoventral boundaries and gradually fills in the entire wing pouch by the mid-late third instar ${ }^{24}$ (Fig. 2c). In contrast, expression of the lac $Z$ reporter gene driven by either mutated quadrant enhancer was not detectable in most early to mid third-instar discs. When detected, expression was only observed at a very low level near the anteroposterior boundary (Fig. $2 \mathrm{~d}, \mathrm{e}$ ). These data, together with the in vitro data from the Mad binding experiments on the $v g$ quadrant enhancer, demonstrate that Mad directly mediates the Dpp-dependent transcription of the $v g$ gene.

The identification of an essential Mad binding site in the quad-
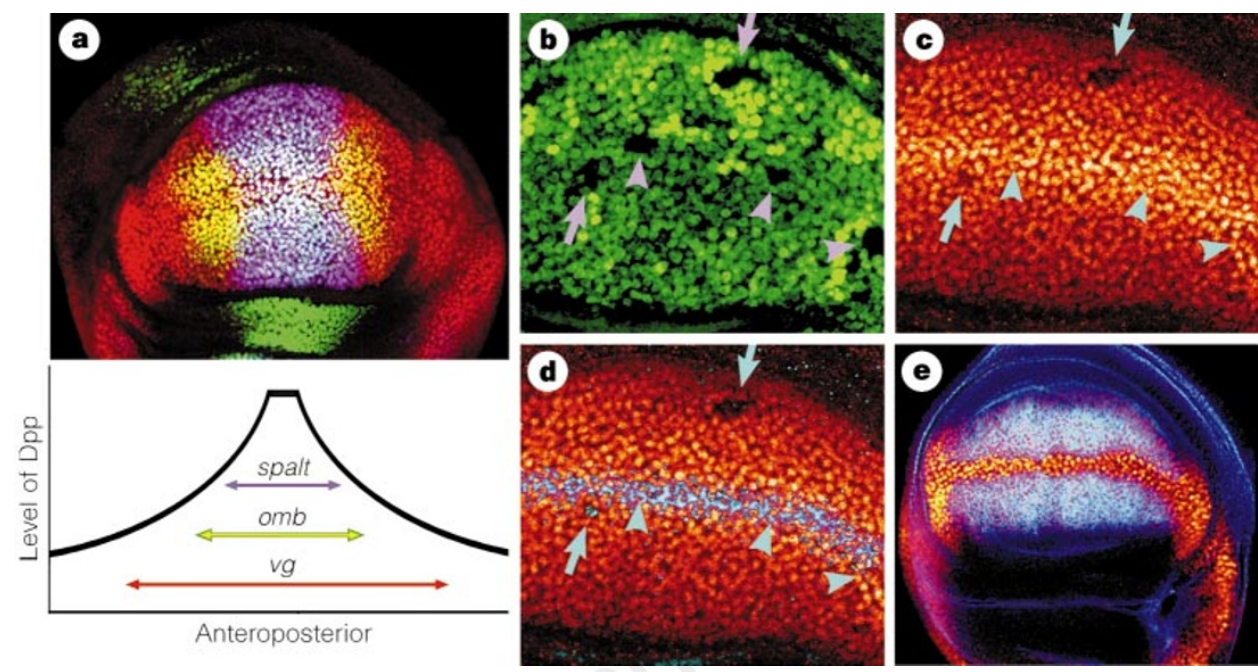

Figure 1 Mad activity is required for $\mathrm{Vg}$ expression in the cells of the developing wing blade. Native $\mathrm{Vg}$ protein expression is shown in red. a, Top, triple-labelled thirdinstar wing disc with nested domains of Spalt (purple and light blue) and Omb (green, and yellow where coexpressed with $\mathrm{Vg}$ ) expression within the broad Vg (red) domain. Bottom, these wing patterning genes are activated over different distances from the Dpp source. b, Mitotic clones homozygous for the hypomorphic Mad $^{1.2}$ allele lack expression of the Myc epitope tag (green). c, $\mathrm{Vg}$ expression in the same disc as b. d, Wingless (Wg) (blue) expression merged with the Vg expression (red) shown in $\mathbf{b}$ marks the dorsoventral boundary. The level of $\mathrm{Vg}$ expression is reduced only in the Mad ${ }^{1.2}$ clone in the future wing blade (arrows), but not in the clones on the dorsoventral boundary (arrowheads). e, Vg expression (red) in the future wing-blade cells is regulated by the vg quadrant enhancer ( $\beta$-galactosidase expression driven by the quadrant enhancer is in light blue and purplish pink). a

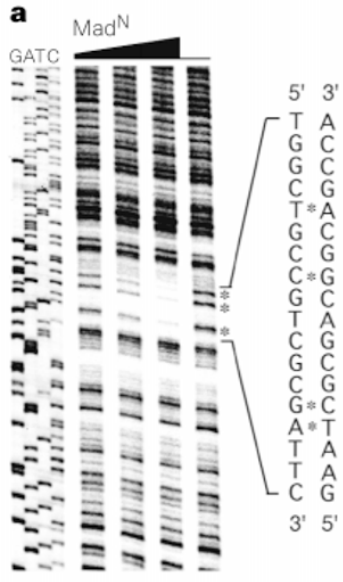

b
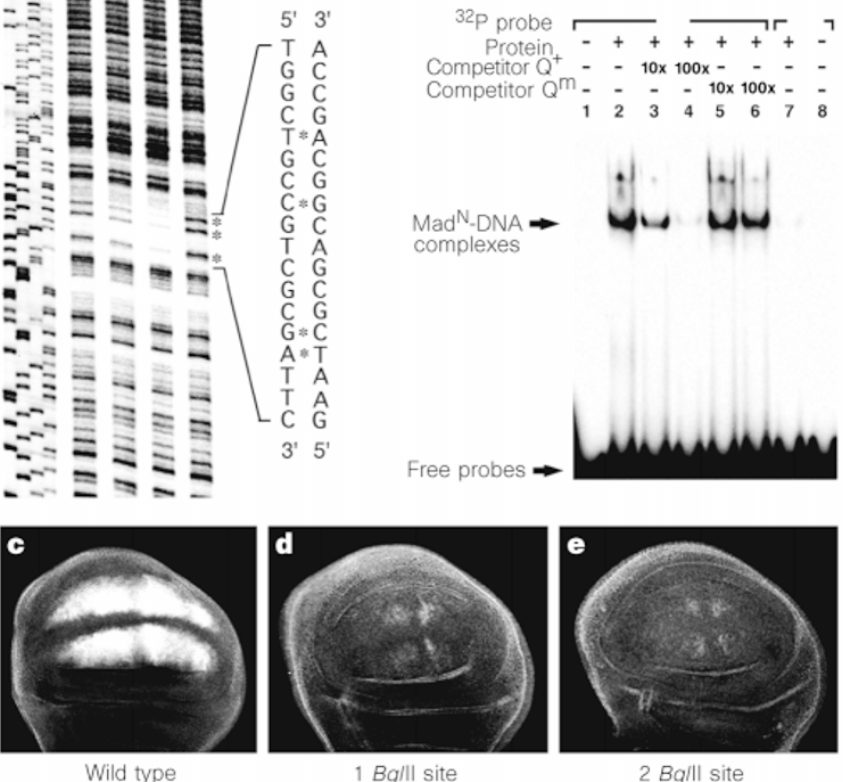

Figure 2 The binding of $\mathrm{Mad}^{\mathrm{N}}$ protein to the $\mathrm{vg}$ quadrant enhancer is sequence specific and essential for activation in vivo. a, DNase I footprint of the $\mathrm{Mad}^{\mathrm{N}}$ protein to the $v g$ quadrant enhancer. An autoradiogram of a denatured polyacrylamide gel used to separate the products of DNase I digestion of $\mathrm{Mad}^{\mathrm{N}}-\mathrm{vg}$ quadrant enhancer complexes is shown (right four lanes) with the DNA sequencing products of the $v g$ quadrant enhancer (left four lanes, marked with their corresponding ddNTP reaction). The schematic representations of the relative amounts of $\mathrm{Mad}^{\mathrm{N}}$ protein used in the reaction (over the right four lanes) shows that $\mathrm{Mad}^{N}$ was increased twofold in the second lane and fourfold in the third lane; the fourth lane is the no-protein control. The DNase I-sensitive bases protected by $\mathrm{Mad}^{\mathrm{N}}$ are marked with asterisks. The double-stranded sequence spanning the protected region is shown. $\mathbf{b}$, Competition gel mobility-shift assay for the binding specificity of $\mathrm{Mad}^{\mathrm{N}}$ to the $\mathrm{vg}$ quadrant enhancer DNA. The presence or absence of each component is indicated by + or -; 10x and 100x indicate the relative molar excess. $\mathrm{Q}^{+}$is the wild-type double-stranded oligonucleotide containing the $\mathrm{Mad}^{\mathrm{N}}$ footprinted interval; $\mathrm{Q}^{\mathrm{m}}$ is the oligonucleotide in which the footprinted interval has been replaced with two $B g / l l$ sites (see Methods for sequences). The $Q^{+}$probe was bound well by Mad $^{N}$ (lane 2) but the $Q^{m}$ probe was not (lane 7). The unlabelled $Q^{m}$ oligonucleotide did not compete efficiently for the $Q^{+}-M^{N}{ }^{N}$ complex formation (lanes 5 and 6), whereas the $Q^{+}$ oligonucleotide did (lanes 3 and 4). c, Expression of $\beta$-galactosidase driven by the wild-type $v g$ quadrant enhancer in a mid-late third-instar wing imaginal disc. d, e, Expression of $\beta$-galactosidase driven by the mutated $v g$ quadrant enhancer in which the 12-bp Mad binding site has been replaced with a Bg/ll site (d) and two tandem $B g / l l$ sites as in $Q^{m}(\mathbf{e})$. The expression level of $\beta$-gal was greatly reduced in these discs compared with the wild-type enhancer (c). The imaginal discs in c-e carry one copy of the reporter gene. 


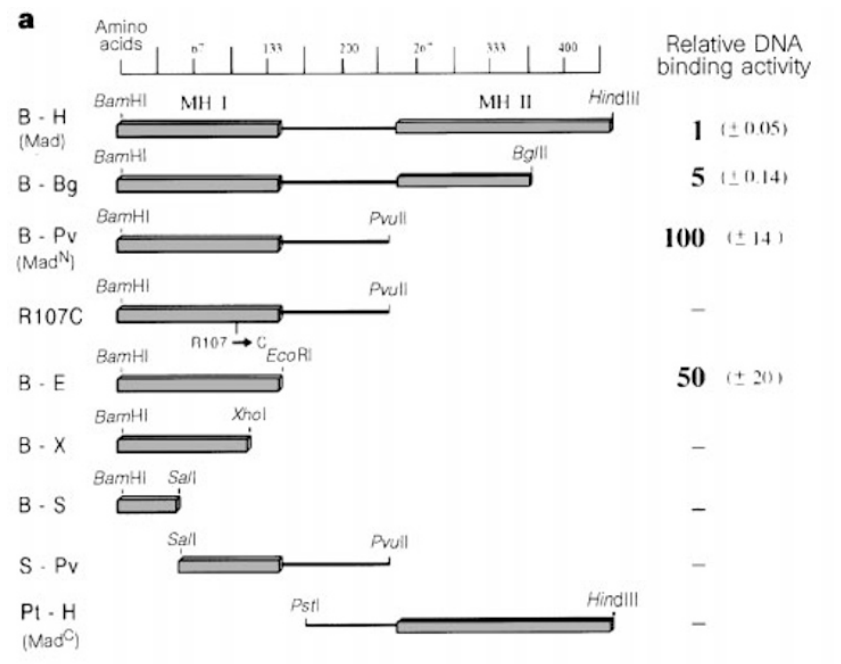

b
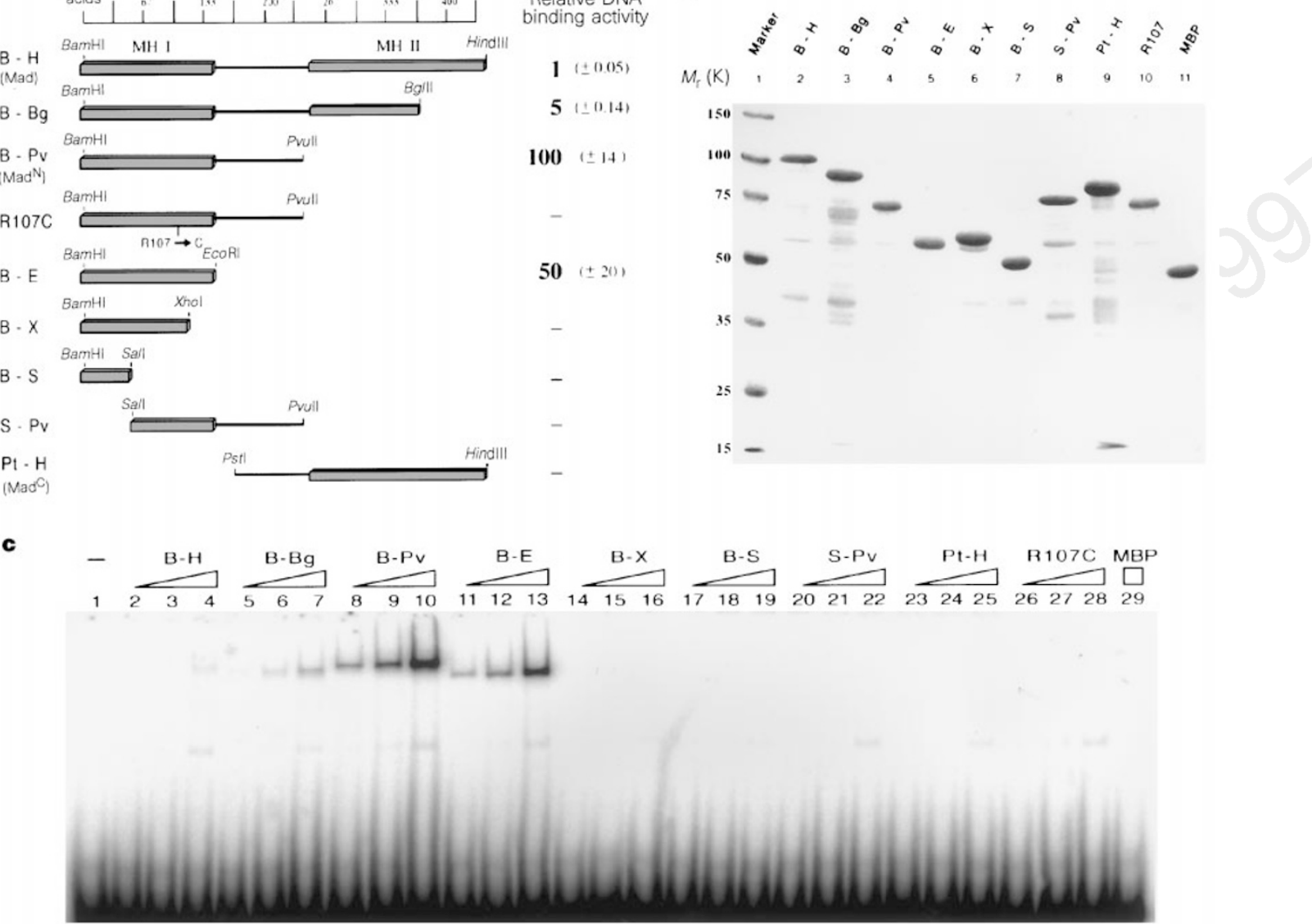

Figure 3 The N-terminal domain of Mad protein $\left(\mathrm{Mad}^{\mathrm{N}}\right.$ ) binds to the $v g$ quadrant enhancer. a, MAD fusions to the $\mathrm{C}$ terminus of MBP or GST for use in DNAbinding assays. Conserved $\mathrm{MH} 1$ and $\mathrm{MH} 2$ regions are shown as boxes, with the intervening linker region indicated by a line. Fusion proteins contain the following MAD amino acids: B-H (Mad), 1-455; B-Bg, 1-372; B-Pv $\left(\mathrm{Mad}^{\mathrm{N}}\right), 1-241$; R107C, 1-241; B-E, 1-159, B-X, 1-120; B-S, 1-48; S-Pv, 49-241; Pt-H (MAD ${ }^{\mathrm{C}}$ ), 167-455. Amino-acid residue number is indicated at the top. Relative DNA binding activity is shown on the right. Protein concentrations were estimated by display on the SDS polyacrylamide gel in $\mathbf{b}$. Data are from $\mathbf{c}$ and two repetitions of this experiment. Standard error is indicated within brackets. b. Coomassie blue-stained 10\% SDS gel showing affinity-purified preparations of MBP fusion proteins used in c. c, Autoradiographic image of a gel mobility-shift assay testing the ability of MBPMad fusions to bind to a ${ }^{32} \mathrm{P}$-end-labelled 20-bp vg double-stranded oligonucleotide. Lane 1, no protein control; lane 24, unfused MBP; remaining sets of lanes contain progressive 5 -fold increases in the proteins labelled as in $\mathbf{a}$ rant enhancer allowed us to localize the Mad DNA-binding domain more precisely. In a series of fusions to the maltose-binding protein (MBP) of Escherichia coli, the effects of deletions from the Mad C and $\mathrm{N}$ termini (Fig. 3a, b) on DNA-binding activity were tested using an oligonucleotide containing the Mad site of the quadrant enhancer (Fig. 3c). The specific DNA-binding activity of full-length Mad protein (B-H, lanes 2-4) was approximately 100-fold lower than that of C-terminally truncated $\mathrm{Mad}^{\mathrm{N}}$ (B-Pv, lanes 8-10); removal of only a portion of $\mathrm{MH} 2$ (B-Bg, lanes 5-7) resulted in an intermediate activity. These results show that $\mathrm{MH} 2$ effectively inhibits DNA binding and suggests a mechanism that might contribute to inactivation of Mad in the absence of Dpp signalling. Removal of the linker region from the C-terminal end of MH1 (B-E, lanes 11-13) caused a slight reduction in binding activity. Without $\mathrm{MH} 1, \mathrm{MH} 2$ plus linker region $\left(\mathrm{Mad}^{\mathrm{C}}\right)$ failed to bind to DNA (Pt-H, lanes 23-25). Removal of the C-terminal (B-X, lanes 14-16) or Nterminal (S-PV, lanes 20-22) portion of the MH1 domain abolished DNA-binding activity. Binding was also abolished by a single amino-acid substitution in Mad (Arg107 $\rightarrow$ Cys) that is the same as that found at position 133 in the Smad2 protein in a colorectal tumour $^{4}$ (R107C, lanes 26-28), demonstrating that this conserved residue is essential for MH1 DNA-binding activity.

We also sought to determine a consensus sequence recognized by
$\mathrm{Mad}^{\mathrm{N}}$. As well as the $v g$ quadrant enhancer, several other Dppresponsive enhancers have been characterized, such as the labial endoderm enhancer ${ }^{27,28}$ and the Ultrabithorax midgut enhancer, for which the Dpp response element has been localized to the 95-bp DI-DII interval ${ }^{29}$. Gel shifts with oligonucleotides representing portions of these enhancers (Fig. 4b, lanes 1-18), and the competition of $\mathrm{Q}^{+}$but not $\mathrm{Q}^{\mathrm{m}}$ for these oligonucleotides (Fig. 4c, lanes 9$12,15-18)$, show that at least one high-affinity $\operatorname{Mad}^{\mathrm{N}}$ binding site is found in each, together with multiple low-affinity sites. Alignment of these sequences and comparison of the relative strength of $\mathrm{Mad}^{\mathrm{N}}$ binding were used to derive a $\mathrm{Mad}^{\mathrm{N}}$ binding-site consensus of GCCGnCGC. The two sites of highest affinity match this consensus perfectly, and three lower-affinity sites contain mismatches at one to three positions (Fig. 4d).

Our results demonstrate that the Mad MH1 region has a sequence-specific DNA-binding domain, and indicate that this DNA-binding activity is important in directing transcriptional activation in response to Dpp signalling. The C-terminal MH2 region, in addition to its previously demonstrated function as a transcriptional activation domain (in the case of Smad1) ${ }^{3}$, inhibits the DNA-binding activity of MH1 in vitro. It is not yet known whether the masking of DNA-binding activity (in addition to cytoplasmic sequestration by receptors ${ }^{8}$ ) is involved in the regula- 
a

$l a b$

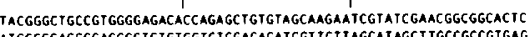

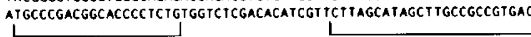

A C

Ubx

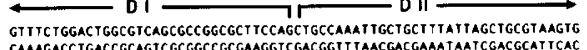

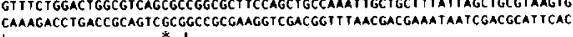
$\frac{\text { A }}{\text { A }}$

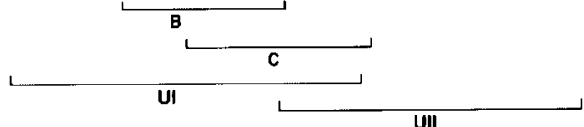

d

lab- $A$

$U b x-A$

lab-C

$U b x-B$

vg

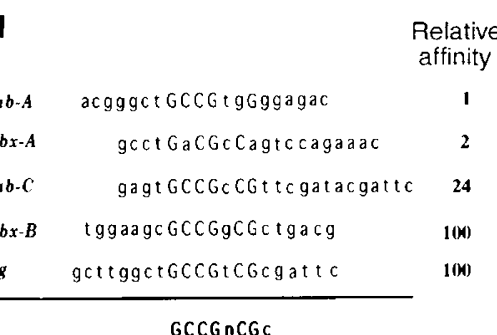

b

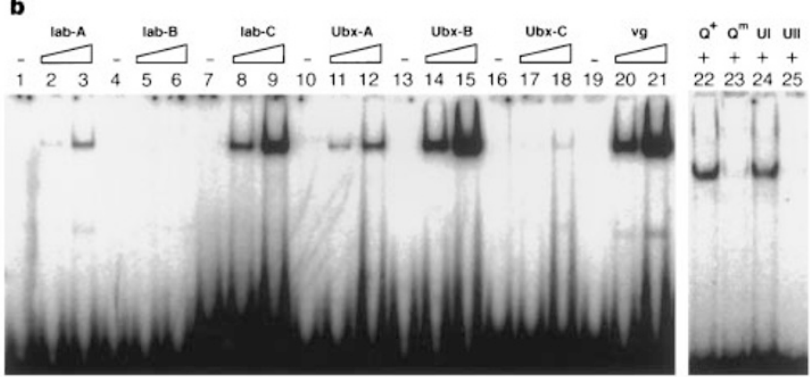

c

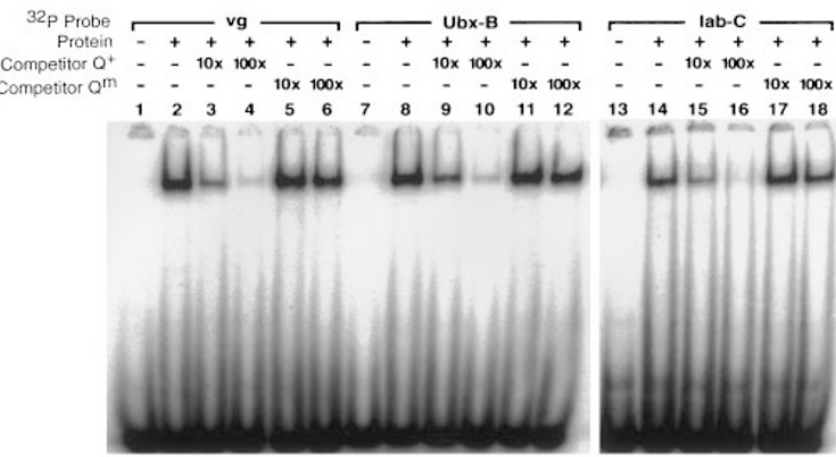

Figure 4 The lab endodermal and Ubx midgut enhancers contain $\mathrm{Mad}^{\mathrm{N}}$ binding sites similar to those in the $\mathrm{vg}$ quadrant enhancer. $\mathbf{a}$, DNA sequences of a portion of the lab endodermal enhancer and of the DI and DII regions of the Ubx midgut enhancer, each of which contains sequences resembling the Mad binding site of the quadrant enhancer. The regions corresponding to the probes used for the gel mobility-shift assay in $\mathbf{b}$ are marked with brackets. The asterisk indicates a base pair that was omitted in the Ubx-A probe. $\mathbf{b}$, Gel mobility-shift assay identifies a high-affinity $\mathrm{Mad}^{\mathrm{N}}$ binding site in the lab enhancer and one in the Ubx DI region. The sequences of the $l a b$ and $U b x$ probes are shown in $\mathbf{a} . v g$ is a 20-bp probe containing the $\mathrm{Mad}^{\mathrm{N}}$ binding site; $\mathrm{Q}^{+}$and $\mathrm{Q}^{\mathrm{m}}$ are 40 -bp probes containing wildtype and mutated versions of the same site. Each set of $30-\mu$ l binding reactions contained (left to right) 0,100 and $500 \mathrm{ng}$ of fusion protein, as indicated by the minus sign and wedge. c, Competition assays for specificity of Mad ${ }^{\mathrm{N}}$ binding to $v g, U b x-B$ and lab-C oligonucleotides. A10- and 100-fold excess of $Q^{+}$or $Q^{m}$ oligonucleotide over labelled $v g, U b x-B$ or $l a b-C$ probe was incubated in binding reactions containing $250 \mathrm{ng}$ of $\mathrm{Mad}^{\mathrm{N}}$. In each case $\mathrm{Q}^{+}$, but not $\mathrm{Q}^{\mathrm{m}}$, competed efficiently for binding to $\mathrm{Mad}^{\mathrm{N}}$ showing that each site is bound with a high degree of sequence specificity. $\mathbf{d}$, Alignment of sequences that are bound by $\mathrm{Mad}^{\mathrm{N}}$ in $\mathbf{b}$. The GCCGnCGc consensus derived from the aligned sequences matches the two highest affinity sites perfectly, contains one mismatch with a moderate affinity site, and contains 2-3 mismatches with two low-affinity sites.

tion of Mad activity by Dpp in vivo. One further mechanistic issue concerns the establishment of nested expression domains of Dppregulated genes in the wing. Different thresholds for response to Dpp could result from different affinities and/or numbers of Mad binding sites in target enhancers. This possibility can be tested once the Dpp-responsive cis-regulatory element(s) of other wingpatterning genes is isolated and characterized.

Note added in proof: Eresh et al. (EMBO J. 16, 2014-2022; 1997) have recently provided evidence that Dpp induces visceral mesodermal expression of $U b x$ by direct binding of dCREB B protein to a CRE element. This CRE is adjacent to a palindromic sequence, termed FP5, which footprints with an embryonic nuclear extract. FP5 is coincident with the high-affinity Mad binding site we identified in the Ubx B oligo. Eresh et al. showed that reporter gene response to Dpp was dramatically reduced by mutation of the CRE but not by mutation of FP5. Thus Dpp-dependent activation of $U b x$ may not require DNA contact by Mad, but rather by dCREB B. These contrasting results for $v g$ and $U b x$ suggest that the mechanism by which Mad mediates transcriptional regulation may vary significantly among the many targets of Dpp signalling.

\section{Methods}

Generation of Mad clones and immunohistochemistry. Mitotic clones homozygous for the $\mathrm{Mad}^{1.2}$ allele were generated by heat-shock induction of FLP recombinase in the progeny of w; $\mathrm{Mad}^{1.2}, \mathrm{P}[\mathrm{ry}+$, hs-neo, FRT] $40 \mathrm{~A} / \mathrm{CyO}$ males (stock provided by V. Wiersdorff, M. Mlodzik and S. Cohen) crossed to $\mathrm{w}^{1118}$, hsFLP1; P[w+, hs-pM] 36F, P[ry+, hs-neo, FRT] 40A female flies. Clone

induction and antibody staining of imaginal discs was performed as previously described $^{24}$.

Production and purification of Mad fusion proteins. For fusions containing the $\mathrm{MH} 1$ domain ( $\mathrm{Mad}$ and $\mathrm{Mad}^{\mathrm{N}}$ ) a BamHI site was introduced by polymerase chain reaction (PCR) $15 \mathrm{bp}$ upstream of the predicted initiator ATG. Fusion of this BamHI site to a BamHI polylinker site at the C terminus of GST or MBP resulted in insertion of the sequence Gly-Ser-Ser-Asn-Arg between GST (or MBP) and MAD. The full-length Mad fusions contained Mad sequences extending from the BamHI site to a HindIII site located within the 3' untranslated region. Truncated fusions were constructed using the restriction sites indicated in Fig. 3a. The R107C point mutation was introduced into the Mad coding region by two-primer site-directed mutagenesis, and was confirmed by sequencing. The GST and MBP fusion proteins were purified by affinity chromatography ${ }^{31}$.

Gel mobility shift and DNasel footprinting assays. DNA-binding assays for Mad fusion proteins were performed in binding buffer $(25 \mathrm{mM}$ Tris, $\mathrm{pH} 7.5$, $80 \mathrm{mM} \mathrm{NaCl}, 35 \mathrm{mM} \mathrm{KCl}, 5 \mathrm{mM} \mathrm{MgCl}, 1 \mathrm{mM}$ DTT, $10 \%$ glycerol (v/v), $50 \mu \mathrm{g} \mathrm{ml}^{-1}$ poly(dI.dC), $50 \mu \mathrm{g} \mathrm{ml}^{-1}$ poly(dA.dT), $150 \mu \mathrm{g} \mathrm{ml}^{-1}$ nonspecific competitor DNA) and separated in $5 \%$ polyacrylamide gels containing $0.5 \times$ TBE. The top strands of the double-stranded oligonucleotides used are indicated in Fig. 4 except for the following, in which underlining shows where $\mathrm{Q}^{+}$and $\mathrm{Q}^{\mathrm{m}}$ differ in sequence: $\mathrm{Q}^{+}$, TTTGTGCTTGGCTGCCGTCGCGATTCG ACAACTTTGG; $\mathrm{Q}^{\mathrm{m}}$, TTTGTGCTTGAGATCTAGATCTATTCGACAACTTT GG; Vg, CTTGGCTGCCGTCGCGATTC. Oligonucleotide probes corresponding to regions of the $v g$ quadrant, $U b x$ midgut, and lab endodermal enhancer sequences were labelled with $\left[\gamma-{ }^{32} \mathrm{P}\right] \mathrm{ATP}\left(6,000 \mathrm{Ci} \mathrm{mmol}^{-1}, \mathrm{NEN}\right)$ and T4 polynucleotide kinase. The probe DNAs for DNase I footprinting were 
synthesized by PCR. DNase I footprinting reactions were processed as described $^{24}$.

Reporter gene construction. Substitution of a single BglII site for the quadrant enhancer Mad binding-site sequence GCTGCCGTCGCG was done by assembling two fragments generated by PCR with $P f u$ polymerase. Expansion of the single BglII site to two tandem sites matching the $\mathrm{Q}^{\mathrm{m}}$ sequence was done by insertion of an oligonucleotide containing $B b s I$ internal sites that allowed for subsequent cleavage and ligation to generate the tandem $B g l I I$ sites. Both sequences were confirmed by sequencing and ligated into the KpnI/NotI sites of the Hsp lacZ-CaSpeR Drosophila transformation vector for the generation of transgenic lines ${ }^{24}$.

Received 20 January; accepted 21 May 1997

1. Graff, J. M., Bansal, A. \& Melton, D. A. Xenopus Mad proteins transduce distinct subsets of signals for the TGFß superfamily. Cell 85, 479-487 (1996).

2. Hoodless, P. A. et al. MADR1, a MAD-related protein that functions in BMP2 signaling pathways. Cell 85, 489-500 (1996)

3. Liu, F. et al. A human Mad protein acting as a BMP-regulated transcriptional activator. Nature $\mathbf{3 8 1}$ 622-623 (1996).

4. Eppert, K. et al. MADR2 maps to 18q21 and encodes a TGF $\beta$-regulated MAD-related protein that is functionally mutated in colorectal carcinoma. Cell 86, 543-552 (1996).

5. Zhang, Y., Feng, X.-H., Wu, R.-Y. \& Derynck, R. Receptor-associated Mad homologues synergize as effectors of the TGF- $\beta$ response. Nature 383, 168-172 (1996)

6. Lagna, G., Hata, A., Hemmati-Brivnlou, A. \& Massagué, J. Partnership between DPC4 and SMAD proteins in TGF- $\beta$ signalling pathways. Nature 383, 832-836 (1996).

. Savage, C. et al. C. elegans genes sma-2, sma-3, and sma-4 genes define a conserved family of TGF- $\beta$ pathway components. Proc. Natl Acad. Sci. USA 93, 790-794 (1996).

8. Macias-Silva, M. et al. MADR2 is a substrate of the TGF- $\beta$ receptor and its phosphorylation is required for nuclear accumulation and signaling. Cell 87, 1215-1224 (1996).

9. Derynck, R. \& Zhang, Y. Intracellular signalling: The Mad way to do it. Curr. Biol. 6, 1226-1229 (1996)

10. Chen, X., Rubock, M. J. \& Whitman, M. A transcriptional partner for MAD proteins in TGF- $\beta$ signalling. Nature 383, 691-696 (1996).

11. Raftery, L., Twombly, V., Wharton, K. \& Gelbart, W. Genetic screens to identify elements of the decapentaplegic pathway in Drosophila. Genetics 139, 241-254 (1995).

12. Sekelsky, J., Newfeld, S., Raftery, L., Chartoff, E. \& Gelbart, W. Genetic characterization and cloning of Mothers against dpp, a gene required for decapentaplegic function in Drosophila melanogaster. Genetics 139, 1347-1358 (1995)

13. Newfeld, S. J., Chartoff, E. H., Graff, J. M., Melton, D. A. \& Gelbart, W. M. Mothers against dpp encodes a conserved cytoplasmic protein required in DPP/TGF- $\beta$ responsive cells. Development 122, 2099 2108 (1996).

14. Wiersdorff, V., Lecuit, T., Cohen, S. M. \& Mlodzik, M. Mad acts downstream of Dpp receptors, revealing a differential requirement for $d p p$ signaling in initiation and propagation of morphogenesis in the Drosophila eye. Development 122, 2153-2162 (1996).

15. Blair, S. Compartments and appendage development in Drosophila. BioEssays 17, 229-309 (1995).

16. Basler, K. \& Struhl, G. Compartment boundaries and the control of Drosophila limb pattern by hedgehog protein. Nature 368, 208-214 (1994).

17. Tabata, T. \& Kornberg, T. Hedgehog is a signalling protein with a key role in patterning Drosophila imaginal discs. Cell 76, 89-102 (1994)

18. Zecca, M., Basler, K. \& Struhl, G. Sequential organizing activities of engrailed, hedgehog and decapentaplegic in the Drosophila wing. Development 121, 2265-2278 (1995).

19. Ingham, P. W. \& Fietz, M. J. Quantitative effects of hedgehog and decapentaplegic activity on the patterning of the Drosophila wing. Curr. Biol. 5, 432-440 (1995).

20. Posakony, L., Raftery, L. \& Gelbart, W. Wing formation in Drosophila melanogaster require decapentaplegic gene function along the anterior-posterior compartment boundary. Mech. Dev. 33, 69-82 (1991).

21. Capdevilla, J. \& Guerrero, I. Targeted expression of the signalling molecule decapentaplegic induces pattern duplications and growth alterations in Drosophila wings. EMBO J. 13, 4459-4468 (1994).

22. Nellen, D., Burke, R., Struhl, G. \& Basler, K. Direct and long-range action of a Dpp morphogen gradient. Cell 85, 357-368 (1996).

23. Lecuit, T. et al. Two distinct mechanisms for long-range patterning by Decapentaplegic in the Drosophila wing. Nature 381, 387-393 (1996).

24. Kim, J. et al. Integration of positional signals and regulation of wing formation and identity by Drosophila vestigial gene. Nature 382, 133-138 (1996).

25. de Celis, J. F., Bario, R. \& Kafatos, F. C. A gene complex acting downstream of $d p p$ in Drosophila wing morphogenesis. Nature 381, 421-424 (1996).

26. Grimm, S. \& Pflugfelder, G. O. Control of the gene optomotor-blind in Drosophila wing developmen by decapentaplegic and wingless. Science 271, 1601-1604 (1996).

27. Chouinard, S. \& Kaufman, T. C. Control of expression of the homeotic labial (lab) locus of Drosophila melanogaster: evidence for both positive and negative autogenous regulation. Development 113 $1267-1280(1991)$

28. Tremml, G. \& Bienz, M. Induction of labial expression in the Drosophila endoderm: response element for $d p p$ signalling and for autoregulation. Development 116, 447-456 (1992).

29. Thuringer, F., Cohen, S. M. \& Bienz, M. Dissection of an indirect autoregulatory response of a homeotic Drosophila gene. EMBO J. 12, 2419-2430 (1993)

30. Eresh, S., Riese, J., Jackson, D. B., Bohmann, D. \& Bienz, M. A CREB-binding site as a target for decapentaplegic signalling during Drosophila endoderm induction. EMBO J. 16, 2014-2022 (1997).

31. Ausubel, F. M. et al. (eds) Current Protocols in Molecular Biology supplement 28, pp. 16.6.1-16.7.7 (Wiley, New York, 1994).

Acknowledgements. We thank K. Vorwerk for technical assistance; M. Hoffmann for discussion; Y. J. Chen for the MAD cDNA clone and help with sequencing; V. Wiersdorff, M. Mlodzik and S. Cohen for the $\mathrm{Mad}^{1.2}$ stock; S. Paddock for help with microscopy; T. Kaufman for the labial endodermal enhancer M. Hoffmann and G. Halder for comments on the manuscript; and J. Wilson for manuscript preparation. K. J. was supported by a genetics predoctoral training grant and the Cremer Scholarship Fund, and part of this work was supported by the Howard Hughes Medical Institute (S.B.C.)

Correspondence and requests for materials should be addressed to A.L. (e-mail: alaughon@facstaff.wisc edu).

\section{errata}

\section{Differential activation of transcription factors induced by $\mathrm{Ca}^{2+}$ response amplitude and duration}

\section{Ricardo E. Dolmetsch, Richard S. Lewis, Christopher C. Goodnow \& James I. Healy}

Nature 386, 855-858 (1997)

The graphs in Fig. 2e were accidentally swapped around during the production process. The correct versions are shown here. e

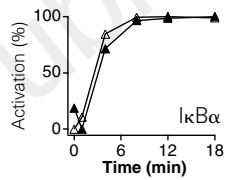

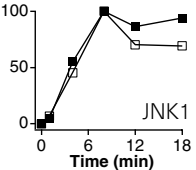

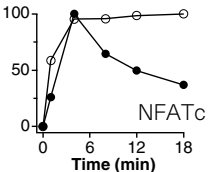

\section{Large-scale tectonic deformation inferred from small earthquakes}

\section{Falk Amelung \& Geoffrey King}

Nature 386, 702-705 (1997)

Owing to an error in the production process, a length scale was omitted from Fig. $2 \mathrm{~b}$ and the shading in Fig. $2 \mathrm{~d}$ did not show up. The corrected figure is shown here.
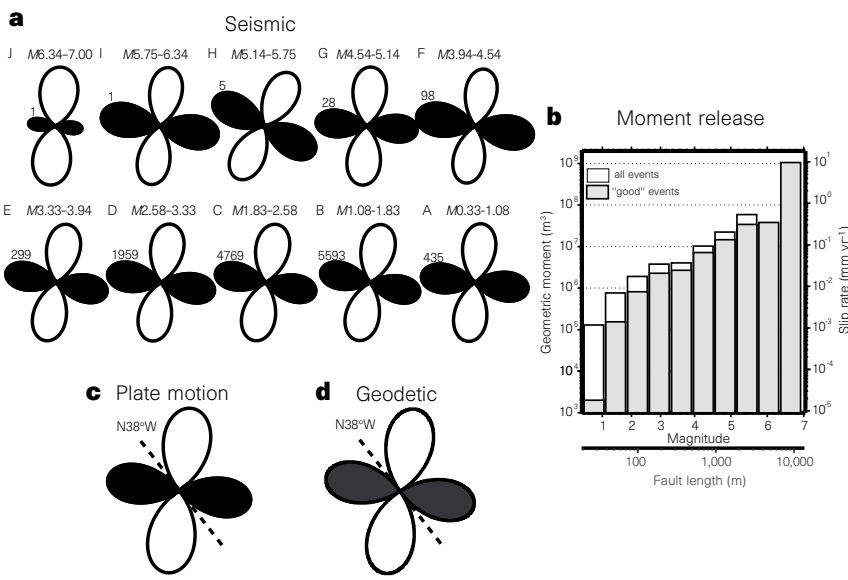